\title{
Incomplete Information in Repeated Coordination Games
}

\author{
2 November 2007 \\ Eric Rasmusen
}

Abstract

Asymmetric information can help achieve a good equilibrium in repeated coordination games. If there is a small probability that one player can play only one of a continuum of moves, that player can pretend to be of the constrained type, and other players will coordinate with him.

Dan R. and Catherine M. Dalton Professor, Department of Business Economics and Public Policy, Kelley School of Business, Indiana University. Visitor (2007-2008), Nuffield College, Oxford University. Office: 011-44-1865 554-163 or (01865) 554-163. Nuffield College, Room C3, New Road, Oxford, England, OX1 1NF. Erasmuse@indiana.edu. http://www.rasmusen.org. This paper: Http://www.rasmusen.org/ papers/goodtype-rasmusen.pdf.

I thank the Indiana Business Economics Brown Bag Lunch and Michael Baye for helpful comments. 


\section{Introduction}

It is well known that coordination games have multiple equilibria, depending on player expectations, even if one equilibrium is pareto superior and players can communicate. This multiplicity is present even in the one- shot game, and just gets worse when the game is repeated. Few of the refinements of Nash equilibrium that have been suggested in the context of other kinds of games help with coordination games, and none has gained more than minimal acceptance.

The problem of multiple equilibria in coordination games has attracted attention from various authors. One way to try to predict which equilibrium is played out is to use the behavioral idea of "focal points" from Thomas Schelling (1960): that a human's attention is drawn to certain equilibria because they look "different". Thus, if a game's equilibria had payoffs of $(1,1),(2,2)$, and $(100,100)$, the focal point would be $(100,100)$. This is a difficult notion to formalize, though: if the alternatives were $(1,1),(99,99)$, and $(100,100)$ would we predict that that the players would end up at $(1,1)$ because it is the most distinctive?

Clearly, the idea of the focal point is important. Philosopher David Lewis (1965) divides the idea of the salience of a choice into two parts. The choice has "primary salience" to a player if he believes it is salient to he himself; it has "secondary salience" if he believes it has salience to other players. Judith Mehta, Chris Starmer \& Robert Sugden (1994, p. 661) add "Schelling salience" to primary and secondary salience, as a choice that "seems obvious or natural to people who are looking for ways of solving coordination problems." In their article they report results of experiments trying to distinguish between primary salience- the answers subjects gave to questions when there was no reward for coordination- and secondary or Schelling salience- the answers when subjects were rewarded for successful coordination. They found that subjects indeed were picking with an eye towards what other subjects would pick; for example when asked to write down any day of the year, only $6 \%$ of the first set of subjects answered December 25 , but $44 \%$ did when they were rewarded for successful cooperation.

A second approach tries to use derive the unique equilibrium from rationality. Gauthier (1975, p. 201) defines the "Principle of Coordination" as that "in a situation with one and only one outcome which is both optimal and a best equilibrium, if each person takes every other person to be rational and to share a common conception of the situation, it is rational for each person to perform that action which has the best equilibrium as one of the possible outcomes." Bacharach ( 1993) Harsanyi \& Selten (1988) and Janssen (2000, 2001) have pursued this approach, trying to add axioms for rational behavior that require players to avoid dominated equilibria.

Repeating the game does not reduce the number of equilibria, but it does introduce a new angle: finding the optimal way to play a game starting without a convention as to the equilibria. What is the optimal strategy for the two players if they must first grope their ways towards coordination by guessing what the other player will do before they end up at the same action and use it thereafter? That is the project in Crawford\& Haller (1990), who find a learning procedure that converges in finite time. 
A third approach is to look at evolution in games. Glenn Ellison (1993), Michihiro Kandori, George J. Mailath \& Rafael Rob (1993), and Peyton Young (1993) take this approach. Start with a population of pairwise- interacting players with different strategies. They play coordination games, and increase or diminish in frequency depending on their payoffs. In such settings, "risk-dominant strategies" emerge as equilibria. In a symmetric two-player setting, this is the strategy a player would choose if he thought there was a $50 \%$ probability of the other player choosing each strategy. The risk-dominant strategy is not necessarily the one with the highest payoff; it balances that against the loss if discoordination does occur.

Risk-dominant equilibria also arise in the single-repetition "global games" of Morris \& Shin (2003). They ask what happens if players have some small uncertainty over what game they are playing out. It turns out that iterated deletion of interim-dominated strategies can then make the risk-dominant equilibrium the unique equilibrium.

I will show below that adding incomplete information changes the repeated game drastically. Kreps, Milgrom, Roberts \& Weber (1982) show that adding a small amount of carefully chosen incomplete information to the model can result in cooperation in the finitely repeated prisoners' dilemma. Fudenberg \& Maskin (1986) show more generally that adding incomplete information can generate any of a wide range of average payoffs in finite repeated games by getting around the backwards induction of the Chainstore Paradox. Their theorem does not apply to many coordination games, since it depends on a "dimensionality condition" that requires payoffs to vary enough between players to allow equilibria to be supported by punishment phases in which one player is able to punish another without hurting himself. Benoit \& Krishna (1985), however, show that if a game has multiple equilibria, as a coordination game does, then a wide range of equilibria can be obtained if the game is repeated enough times by using the threat of punishment phase in an inferior equilibrium to enforce the desired behavior.

I will not be be able to reduce the number of equilibria in the one- shot game, but I will show that with a small amount of incomplete information and enough repetitions any perfect bayesian equilibrim of even a finitely repeated two-player game will achieve arbitrarily close to the optimal average payoff.

The results will not depend on careful specification of the incomplete information, and it is robust to out-of-equilibrium beliefs. There will be no assumption that "Players are either of type $x=0$ or type $x=100$ (with small probability), but never any other value of $x$." Nor will I specify anything like, "Out of equilibrium, the deviating player is believed to be of type $x \in[0,34]$." Rather, the intuition is that in coordination games, no player has an incentive to hurt other players, so any attempt to "fool" other players by pretending to be of a particular type will be eagerly accepted by them. This intuition is partly present in the intuition behind the Gang of Four Theorem of Kreps, Milgrom, Roberts \& Weber (1982); here, it applies better and so the result is easier to achieve.

\section{The Repeated Complete-Information Coordination Game with Two Players}


Consider a ranked coordination game with $n=2$ players indexed by $i$ who simultaneously choose actions $x_{1}, x_{2}$ from the interval $[0,100]$. The per-period payoff to player $i$ is $\pi\left(x_{i}, x_{-i}\right)$ with:

$$
(a) \forall x, \frac{\partial \pi(x, x)}{\partial x}>0 \quad(b) \pi(0,0)>\pi\left(x_{i}, x_{-i}\right) \text { if } x_{i} \neq x_{-i}
$$

Assumption (a) says that a player's payoff rises if he chooses a higher action and the other player chooses the same action as he does. Assumption (b) says that if the player's choose different actions, their payoffs are lower than if they coordinated on $(0,0)$.

We will normalize to $\pi(0,0)=0$ and $\pi(100,100)=100$, which is to say the per-period payoff is 0 when both players choose $x=0$ and 100 when they pick $x=100$. The assumptions then imply that coordination on $x>0$ yields positive payoffs and discoordination yields negative payoffs.

If the game is unrepeated and $T=1$, it has a continuum of pure strategy equilibria, with $x$ on the continuum from 0 to 100 , as well as mixed strategy equilibria. All players prefer the equilibrium in which $x=100$.

Which equilibrium will be played out, depends on player expectations. A reasonable prediction is $x=100$ because it is pareto superior to all other equilibria, a focal point. An equally special equilibrium, however, is $x=0$. It is easy to imagine how the players could be caught in any equilibrium - if the game were preceded by a cheap talk announcement by a malicious outsider that he expected them all to choose $x=1$, for example, or after these players or others they knew about had a history of playing $x=5$ for many periods.

Let the game be repeated a possibly infinite number $T$ times, with the players observing each other's strategies after each round and with no discounting.

If $T \geq 2$, equilibrium outcomes and strategies both become more numerous. Let us classify them as follows:

In a time-dependent equilibrium, some player's strategy in a round depends on which round number it is. If the strategies are the same in each round, the equilibrium is time-independent.

In a history-dependent equilibrium, some player's strategy in a round depends on the history of play up to that point. If the strategies do not depend on past play, the equilibrium is history- independent.

The following examples illustrate the definitions. 


\begin{tabular}{|c|c|c|c|}
\hline & \multicolumn{2}{|c|}{ Time } \\
\hline & & Independent & Dependent \\
\hline \multirow{2}{*}{ History } & Independent & Play 10 in each round. & $\begin{array}{l}\text { Play } 20 \text { in the first round } \\
\text { and } 25 \text { in the second. }\end{array}$ \\
\hline & Dependent & $\begin{array}{l}\text { Play } 30 \text { in each round unless } \\
\text { someone deviates, in which case } \\
\text { play } 30 \text { in the second round. }\end{array}$ & $\begin{array}{l}\text { For the first } 50 \text { rounds, player } 1 \\
\text { picks } 2 \text { and the other players pick } 14 . \\
\text { For the last } 10,000 \text { rounds } \\
\text { everyone picks } 100 \text { unless someone } \\
\text { deviates. If someone deviates, all pick } 0 \\
\text { for the remainder of the game. }\end{array}$ \\
\hline
\end{tabular}

\section{Table 2: Two Dimensions}

Note that the history-dependent equilibria expand the number of possible outcomes beyond coordination on some number between 0 and 100 in each period to allow many periods of equilibrium discoordination. Benoit \& Krishna (1985) show that a wide array of outcomes might be observed in equilibrium, supported by punishment strategies similar to example (4)'s. The players choose any pattern of actions the modeller may wish in the first $S$ periods, because in equilibrium they all play $x=100$ in the last $(T-S)$ rounds, but if anybody deviates earlier they all play $x=2$. The observed actions, for example, might be $(10,2),(7,7),(8,3)$, and then $(100,100)$ for the last 200 rounds. As the example shows, repetition of the game does not solve the problem of multiple equilibria, and in fact, even more outcomes become possible. The average payoff could even be negative, if the equilibrium has many periods of discoordination, so long as the average payoff is not below the discoordination payoff.

\section{The Incomplete-Information Coordination Game: A One-Action Player}

Let us modify the game in the spirit of Kreps at al. (1982), by adding a small amount of incomplete information. Players are of two types. With some arbitrarily small probability $p>0$, a player $i$ is "constrained" to play $x_{i}=z_{i}$, in every round of the game, where $z_{i}$ is chosen from [0, 100] using a atomless density $f\left(z_{i}\right)$ such that $f(100)>0$. If player $i$ is not constrained, he is "free".

What is essential is that there be some possibility that a player will choose $x=100$ and stick with it. This might be because he is truly constrained, or because he misunderstands the rules of the game, because he is irrational and thinks all players will make the same choice as he does, because he wishfully thinks that the equilibrium will be the pareto-optimal one (perhaps having 
read some of the references above) or because he thinks, for whatever reason, that if he starts with $x=100$ the other players will join him.

In the modified game, some equilibria disappear, as Example 1 shows.

Example 1. Suppose $T=20$ and the payoff from discoordination is -500 . Is it an equilibrium for a free player to follow the strategy $x=5$ in every period and for a constrained player of type $z$ to play $x=z$ ? No.

Consider what happens if player 1 , although free, deviates to $x=100$ in the first round. Is it a best response for player 2 , if free, to play $x=5$ in the second round? That depends on player 2's beliefs, which are generated by Bayes's Rule:

$$
\operatorname{Prob}\left(z_{1}=100 \mid x_{1}=100\right)=\frac{\operatorname{Prob}\left(x_{1}=100 \mid z_{1}=100\right) * \operatorname{Density}\left(z_{1}=100\right)}{\operatorname{Prob}\left(x_{1}=100 \mid z_{1}=100\right) * \operatorname{Density}\left(z_{1}=100\right)+\operatorname{Prob}\left(x_{1}=100 \mid z_{1}=\operatorname{free}\right) * \operatorname{Prob}\left(z_{1}=\operatorname{free}\right)}
$$

The priors tell us that Prob(player 2 is free $)=1-p$ and Density $\left(z_{1}=100\right)=f(100) p$. In the proposed equilibrium, $\operatorname{Prob}\left(x_{1}=100 \mid z_{1}=100\right)=1$ and $\operatorname{Prob}\left(x_{1}=100 \mid z_{1}=\operatorname{free}\right)=0$. Thus, equation (2) becomes

$$
\operatorname{Prob}\left(z_{1}=100 \mid x_{1}=100\right)=\frac{(1) * f(100) p}{(1) * f(100) p+(0) *(1-p)}=1
$$

After the first round, Player 2 therefore believes that Player 1's type is $z_{1}=100$, so he concludes that $x_{1}=100$ for all future rounds. Player 2's best response is not $x=5$, but to imitate Player 1's action, deviating to $x_{2}=100$. If both players then stick with $x=100$, their payoffs are $(-500+19(100),-500+19(100))$ compared to the $(20(5), 20(5))$ they would have gotten in equilibrium. Thus, Player 1's deviation has been profitable.

It is not true, however, that the only equilibrium will be for a free player to start with $x=100$ and to choose in the second and succeeding periods whatever the other player chose in the first period. If $x=99.9$, it is not worth bearing the initial cost of -500 to deviate. Rather, what we can say is that for large enough $w$ a time- independent equilibrium strategy must have a player beginning with $x=w$ and then choosing in the second and succeeding periods whatever the other player chose in the first period. In such an equilibrium, the equilibrium payoff is $(20 w, 20 w)$. The optimal deviation is to $x=100$, which generates a deviation payoff of $(-500+19(100),-500+19(100))$. There is no incentive to deviate from equilibrium if and only if $w \geq 92.5$.

Example 1 is the essence of this paper. If information is incomplete, then a player can break out of a bad equilibrium at some cost by pretending to be of an unusual type. If the game is repeated long enough, it is worthwhile to bear that cost.

In fact, if $T$ is large enough, the game has a much smaller interval of equilibria and the average payoff becomes arbitrarily close to 100 . 
Proposition 1: For any $\epsilon$, there exists $T$ large enough that in all pure-strategy equilibria the average payoff approaches within $\epsilon$ of the optimum:

$$
\forall \epsilon>0, \exists T: \frac{\sum_{t=1}^{T} \pi_{i t}}{T}>100-\epsilon
$$

Proof. The probability that a player is constrained is an arbitrarily small $p$, so we the effect that the presence of truly constrained players have on the average equilibrium payoffs will be less than $\epsilon$.

Let the equilibrium with the lowest average payoff call for the players to first choose $(a, b)$ with $a$ or $b$ or both not equal to 100 in round $t_{1}$. Without loss of generality, suppose that player 1 chooses $a \neq 100$.

The minimum bound on the payoff is set by player 1 having the deviation option to choose $x=100$ in that period and convince player 2 that player 1 is constrained of type $z=100$. Both players would choose $x=100$ for every succeeding round. This would generate a payoff of $\pi(100, b)+$ $100(T-1)$, where $\pi(100, b)$ is the discoordination payoff that arises from that particular deviation, since there would be one period of discoordination and all other periods will have per-period payoffs of 100. This strategy will have an average payoff of

$$
\frac{\pi(100, b)}{T}+\frac{100(T-1)}{T}=100+\frac{\pi(100, b)}{T}-\frac{100}{T} .
$$

If $T$ is large enough, the last two terms, which are both negative, shrink to less than whatever small amount $\epsilon$ we might choose. Q.E.D.

The equilibria will be in actions with an average payoff in the interval [100 $-\epsilon, 100]$ for some $\epsilon$ that depends on $T$. This set of equilibria does not depend heavily on the out-of-equilibrium payoffs-just for one period of discoordination loss- and therefore it is not necessarily the same as the set of risk-dominant equilibria. It could be, for example, that for $x$ in $[0,50]$ the discoordination payoff if the other player chooses a different $x$ is -1 , but for $x$ in $(50,100]$ it is -5000 , in which case the risk-dominant equilibrium would be $(50,50)$, not $(100,100)$.

\section{The Incomplete-Information Coordination Game: A Tit-for-Tat Player}

With small probability $p$, player 1 is "constrained" to play tit-for-tat: in equilibrium he begins with whatever $x_{1}=z$ maximizes his equilibrium payoff, but thereafter he plays the action $y$ that is played by the most other players in $(t-1)$, randomizing among the possibilities if there is a tie for action $y$.

Equilibrium is very much as earlier. We can get cooperation except in the first, and last periods, I think. Maybe not, though- this is tricky. 
Suppose 20 every time is the eq. One person deviates to 100 in the first period. A second person then will deviate to 1 in the second period. Then everybody will deviate to 100 in the third period.

\section{The Repeated Complete-Information Coordination Game with More than Two Players}

Now let us allow for more than two players.

Consider a ranked coordination game with $n \geq 2$ players indexed by $i$ who simultaneously choose actions $x_{1}, \ldots, x_{n}$ from the interval $[0,100]$. If $\# x_{i}$ players choose the same action $x_{i}$, the per-period payoff to player $i$ is $\pi_{i}\left(x_{i}, x_{-i}, \# x_{i}\right)$, with:

$$
\begin{aligned}
& \left(a^{\prime}\right) \frac{\partial \pi_{i}\left(x_{i}, x_{-i}, \# x_{i}\right)}{\partial x_{i}} \geq 0 \\
& \left(b^{\prime}\right) \frac{\Delta \pi_{i}\left(x_{i}, x_{-i}, \# x_{i}\right)}{\Delta \# x_{i}}>0 \\
& (c) \frac{\partial^{2} \pi_{i}\left(x_{i}, x_{-i}, \# x_{i}\right)}{\partial x_{i} \partial x_{j}}=0 \\
& (d) \pi_{i}\left(0, x_{-i}, n\right)>\pi_{i}\left(100, x_{-i}, n-1\right), \\
& (e) \pi_{i}\left(w, x_{-i}, l\right)>\pi_{i}\left(w^{\prime}, x_{-i}, l-1\right) \forall l, w, w^{\prime} \neq x
\end{aligned}
$$

Assumption (a') says that the payoff to player $i$ rises or stays the same as the magnitude of the group action $x_{i}$ rises- from 88, say, to 89. Assumption (b') says that the payoff to choosing action $x_{i}$ rises from being in a bigger group.

Assumption (c) says that the payoff to player $i$ from choices made by players who choose discoordinating actions does not depend on which actions they choose. I might not need this one.

Assumption (d) says that group size matters more than action size: the payoff to $i$ from choosing $x_{i}=0$ in a group of $n$ is bigger than from choosing $x_{i}=100$ in a group of size $n-1$. Assumption (e) is a more general version of (d), saying that a larger group always gets a bigger payoff, no matter what the size of the action. I probably do not need these for my $N=3$ case.

An example (for which I thank Michael Rauh and Michael Baye) is:

$$
\pi_{i}\left(x_{i}, x_{-i}, \# x_{i}\right)=\left[\# x_{i}\left(1+\frac{x_{i}}{1000}\right)-n\right](100 / 1.1 n)
$$

or, without our normalization of $\pi_{i}\left(0, x_{-i}, n\right)=0$ and $\pi_{i}\left(100, x_{-i}, n\right)=100$,

$$
\pi_{i}\left(x_{i}, x_{-i}, m\right)=\# x_{i}\left(1+\frac{x_{i}}{1000}\right)
$$

Example 2. Let there be four players, and consider the equilibrium $(5,5,5,5)$. Suppose player 1 deviates to $x_{1}=10$ in the first period. Even believing that player 1 is of type $z=10$, a unilateral 
switch by one of the other three players from 5 to 10 would be unprofitable if $\pi_{i}(x=5, m=3)>$ $\pi_{i}(x=10, m=2)$. Thus, this would be an equilibrium outcome. (not quite an equilbirium, since 5 is not a best rsponse to $(10,10,10)$ in the first period).

\section{Three Players}

With three players and these assumptions, we do get near-optimal coordination.

Four or More Players

With three players and these assumptions, we do NOT get near-optimal coordination.

Dropping Assumption (b) $\frac{\delta \pi_{i}\left(x_{i}, m\right)}{\delta m}>0$

Everything works the same if $n=2$, of course, since assumption (b) is redundant for that case.

The intuition is similar when we move from two to three players, but a complication arises. If Player 1 deviates from an inefficient equilibrium by choosing $x_{1}=100$, Player 2 cannot unilaterally create coordination by switching to $x_{2}=100$, because Player 3 must switch too.

That is why there are discoordination equilibria too, as mentioned but not explained earlier. Two examples will illustrate:

(1) Let $p_{i}=-1, N=4$. A Nash equilibrium in the one-shot game is $(0,0,80,80)$.

(2) Let $N=3 . \pi(0,20,80)=(-1,-1,-1)$. Let $w$ be any number on $[0,1]$ except 0,20 , and 80 . $\pi(w, 20,100)=(-10,-2,-2) \cdot \pi(0, w, 80)=(-2,-10,-2) \cdot \pi(0,20, w)=(-2,-2,-10) \cdot p=-20$ for any other discoordination permutation.

A Nash equilibrium in the one-shot game is $(0,20,100)$.

The difference between these two examples is that in Example 1 players 1 and 2 would be no worse off if each switched unilaterally to $x=100$, so the discoordination equilibrium is less plausible.

Because action by a single player cannot restore full coordination, incomplete information will not be as general a solution to the coordination problem now as it was in the two-player games. Consider how the possibility of a player constrained to play $x=1$ would affect the discoordination equilibrium in Example 2. If the first-period choices were $(1, .2, .8)$, Players 2 and 3 would each conclude that player 1 would play $x_{1}=1$ in the second period. But in that case, if either switches unilaterally to $x=1$, their payoffs will fall from -2 to -20 .

Nonetheless, there are two ways the incomplete information argument can be adapted to multiplayer games, by applying a dominance argument in an important special case, and by changing the kind of incompleteness. 
First, let us apply the dominance argument. We will now confine ourselves to a special case, the case in Example 1, in which $p_{i}=-v$ for some number $v$. This means that the discoordination payoff is the same regardless of how many players choose the same $x$, so long as even one of them diverges, and that payoff does not change with the size of the divergence. Being discoordinated is like being pregnant: the players are either coordinated or discoordinated.

WAIT: WHY WILL THIS WORK? .1 is a best response if all the other players choose it.

Let us define strategy $s_{i}$ to be "weakly dominated" if its payoff for player $i$ is (a) no higher than that of any other strategy regardless of the strategies other players choose and (b) is lower for some other strategies they might choose: $\pi_{i}\left(s_{i}, s_{-i}\right) \leq \pi_{i}\left(s_{i}^{\prime}, s_{-i}\right) \forall s_{i}^{\prime}, s_{-i}$ and $\pi_{i}\left(s_{i}, s_{-i}\right)<\pi_{i}\left(s_{i}^{\prime \prime}, s_{-i}^{\prime \prime}\right)$ for at least one $s_{i}^{\prime \prime}, s_{-i}^{\prime \prime}$.

The Weak Dominance Refinement: Strategy combination $S_{1}$ is not an equilibrium if it includes a weakly dominated strategy and there exists a Nash equilibrium strategy combination $S_{2}$ that does not.

The weak dominance refinement does not involve any iteration and it applies to equilibrium strategies off the equilibrium path as well as on it. Though weak, this is not an obviously correct refinement, since some equilibria economists generally accept are in weakly dominated strategies. Notably, the unique equilibrium in a Bertrand game of charging price equal to marginal cost is weakly dominated by choosing a higher price. The weak dominance refinement would not rule out that equilibrium, since it is unique, but I mention it as a caution not to accept the refinement blindly. Instead, consider my applications below and decide if you think it rules out plausible equilibria in any of them.

In the complete-information coordination game, the weak dominance refinement rules out some (but not all) equilibrium strategies with a zero payoff, but no positive equilibrium payoffs.

The weak dominance refinement rules out the coordination equilibrium with $x=0$. It also rules out any equilibrium in which some player mixes over a continuum. Doing so yields an expected payoff of zero in any strategy combination, because two players choosing the same $x$ has infinitesimal probability. If a player chose $x=z>0$ instead, and so did all the other players, his payoff would rise to $z$.

On the other hand, the weak dominance refinement does not rule out mixed strategy equilibria that do not mix over a continuum, e.g., each player mixing between .2 and .7 .

Nor does it rule out all zero-payoff equilibria. Nash equilibria in which more than two players choose different values of $x$ as pure strategies survive. The equilibrium in Example 1 is an example. ${ }^{1}$ For example, $(.2, .5, .9)$ is a Nash equilibrium because no single player's deviation would raise the payoff above zero. The strategies are undominated because each of them is a best response to itself;

\footnotetext{
${ }^{1}$ These will disappear in the incomplete information game. Someone would deviate to $\mathrm{x}=1$ and the rest would follow. If it were $(.2, .5,1)$, the player choosing $\mathrm{x}=.2$ would deviate to 1 .
} 
e.g., .2, would be the strictly best response if the other players were to also choose .2 .

Now apply incomplete information.

All free players continuing to choose $x$ in the succeeding rounds is still a Nash equilibrium if $n>2$. They expect to have discoordination in all $T-1$ of those rounds, but if a single player $j$ unilaterally deviates to $x_{j}=1$ to try to match the believed-to-be- constrained player $i$, he cannot prevent discoordination from continuing, so his deviation will not raise his payoff above zero.

Continuing to choose $x$ is a weakly dominated strategy for player $j$, however, because a deviation to $x_{j}=1$ either keeps his payoff at zero, or, if all $n-2$ other players also choose $x_{k}=1$, it raises his payoff to 1 . Hence, if we rule out weakly dominated strategies, player $j$ must choose $x_{j}=1$ in the second round, and so must all the other players. But then, a deviation by free player $i$ to $x_{i}=1$ in round 1 may be profitable for him. This eliminates many stationary equilibria, except for ones with $x=1$ and ones with $x$ close to 1 .

The second approach to the multi-player game is to keep the game general, but to change the way incomplete information enters. Suppose that ${ }^{*}$ each period* a player might be transformed into a one-move player. Then we can use backwards induction. It is possible that in period 1, player 1 will change, in period 2 player 2 changes, etc. But if that is so, they will pretend to change too.

Suppose all but one player has chosen $x=1$. The last player will deduce that the others are one-move players, and will change to $x=1$.

Suppose all but two players have chosen $x=1$. The next-to-last player will deduce that the earlier players are one-move players and will continue to pick $x=1$. He knows that if he picks $x=1$ too, the last player will pick $x=1$. So he does.

Suppose all but $m$ players have chosen $x=1$. The last-but $m-1$ player will deduce that the earlier players are one-move players and will continue to pick $x=1$. He knows that if he picks $x=1$ too, the next player will pick $x=1$. So he does.

This induction proceeds player by player, so if there are $N$ players and they begin with the expectation of not playing $x=1$ then it will take $N$ periods of discoordination before periods of coordination at $x=1$ begin. The number of repetitions $T$ must be great enough for every player in the sequence to be willing to do his part. The ordering of hte players in the sequence may help, because it can be the player who suffers least during the discoordination who makes the first deviation, the one who suffers second-most who makes the second deviation, and so forth. I will not try to prove all that. But what is easy to see is that if $T$ is big enough, the induction deviation will work, in which case coordination at $x=1$ will be immediate.

\section{Mixed Coordination-Conflict Games}

Incomplete information can actually hurt in mixed coordination- conflict games, by destroying the possibility of pure-strategy equilibria. I will show this in the example of the finitely repeated 
battle of the sexes. First, we will need to look at the game with complete information.

Table 2: The Battle of the Sexes

\begin{tabular}{cccc} 
& & \multicolumn{2}{c}{ Woman } \\
& & Fight & Ballet \\
Man & & A,B & 0,0 \\
& Ballet & 0,0 & B,A
\end{tabular}

Payoffs to: (Man, Woman). $A>B$.

The one-shot game of Table 2 has two pure strategy equilibria, (fight, fight) and (ballet, ballet), and a mixed strategy equilibrium. in which the man plays fight with probability $m=A /(A+B)$ and the woman with probability $w=B /(A+B)$.

The repeated game has many equilibria, but let us focus on four of them. Three are timeindependent equilibria in which the three one-shot equilibria are repeated. The total payoffs of the pure-strategy equilibria are $(T A, T B)$ and $(T B, T A)$.

For comparison later, it will be useful to lay out the total payoffs of the mixed-strategy equilibrium for at least one player. The man's expected payoff $V_{m}(f i g h t, t)$ if he plays fight is made up of the $w$ he receives if the woman also plays fight, plus the 0 he receives if she plays ballet, plus the continuation value $V_{m}(f i g h t, t+1)$ of the game:

$$
V_{m}(\text { fight }, t)=w A+(1-w)(0)+V_{m}(\text { fight }, t+1) .
$$

If the man chooses ballet, his expected payoff is made up of the 0 he receives if the woman plays fight, plus the $B$ he receives if she plays ballet, plus the continuation value $V_{m}($ ballet,$t+1)$ of the game:

$$
V_{m}(\text { ballet }, t)=w(0)+(1-w)(B)+V_{m}(\text { ballet }, t+1)
$$

In a mixed-strategy equilibrium the payoffs from the two pure strategies must be equal, so $V_{m}($ fight,$t)=V_{m}($ ballet,$t)$ and $V_{m}($ fight,$t+1)=V_{m}($ ballet,$t+1)$. Solving $w A=(1-w) B$ is what yields the woman's mixing probability $w=B /(A+B)$. The man's one-shot expected payoff is then $A B /(A+B)$, which is less than $B$ since $B<A+B$. The man's expected payoff (and analogously the woman's) in the mixed- strategy equilibrium is lower even than in the pure-strategy equilibrium he likes least.

The fourth equilibrium of the repeated game to be analyzed is a history-dependent one: what I will call the "war of attrition" equilibrium. It has two phases. In the first, the attrition phase, the man plays fight with probability $m_{t}$ and the woman plays fight with probability $w_{t}$ in period $t$. 
The second phase, the victory phase, begins if the outcome is ever (ballet, ballet), in which case the players continue to play (ballet, ballet); or the outcome is ever (fight, fight), in which case they continue to play (fight, fight). Note that if the man "gives in" and chooses ballet but the woman chooses fight in that same period, the attrition phase continues.

The value of the man's overall payoff if he chooses fight is made up of the payment of $A$ he receives this period if the woman also chooses fight or no current payment if she chooses ballet, plus the value of the state at the end of the period. That state is either victory for the man, a prize worth $A(T-t)$, or continuation of the attrition phase, the value $V_{m}(f i g h t, t+1)$ :

$$
V_{m}(\text { fight }, t)=w_{t} A+\left(1-w_{t}\right)(0)+\left(w_{t}\right) A(T-t)+\left(1-w_{t}\right) V_{m}(\text { fight }, t+1)
$$

If the man chooses ballet, his payoff is, similarly:

$$
V_{m}(\text { ballet }, t)=w_{t}(0)+\left(1-w_{t}\right)(B)+\left(w_{t}\right) V_{m}(\text { ballet }, t+1)+\left(1-w_{t}\right) B(T-t) .
$$

How do the mixing probabilities compare to the repeated mixed- strategy equilibrium? Suppose the mixing probabilities were the same in the two equilibria: $w_{t}=w=B /(A+B)$. We know that $V_{m}($ fight,$t+1)=V_{m}($ fight,$t+1)=V$, so the expected continuation payoffs from fight and ballet would be $(B /(A+B)) A(T-t)+(A /(A+B)) V$ and $(B /(A+B)) V+(A /(A+B)) B(T-t)$. The continuation payoff from fight would be higher. Equality of $V_{m}($ fight, $t)$ and $V_{m}($ ballet, $t)$ can only be restored by reducing $w$. Thus, $w_{t}<B /(A+B)$. The woman must have a lower probability of choosing fight to make the man still indifferent between fight and ballet when he has the extra prospect of a victory phase. The potential victory phase becomes shorter and shorter as $T$ approaches, however, so $w_{t}$ approaches $B /(A+B)$ as $t$ approaches $T$.

The man's total payoff is higher in the war of attrition equilibrium than in the historyindependent mixed-strategy equilibrium. Compare $V_{m}($ ballet, $t$ ) in the war of attrition (equation (12)) and in the mixed-strategy equilibrium (equation (10)). First, since $w_{t}<w$, the man has a bigger immediate expected payoff in the war of attrition. Second, he has probability $1-w_{t}$ of reaching the woman's victory phase, which with its sure payoff of $B$ each period for him has a higher per-period expected payoff than the $w_{t} A+\left(1-w_{t}\right) B$ of the mixed-strategy equilibrium ( again, since $w_{t}<w$ and we know that $\left.w A+(1-w) B=A B /(A+B)<B\right)$. Third, if the attrition phase continues, he can continue to play ballet and have a higher immediate expected payoff and some probability of escaping to the victory phase. If the attrition phase continues from there, he will continue to have a higher current payoff and a probability of a higher continuation payoff until the last period, when $w_{t}=w$ and the continuation payoffs are zero since that is just like the one-shot game.

The man's total payoff is lower in the war of attrition equilibrium than in the (ballet, ballet) pure strategy equilibrium. In period $T$, the war of attrition payoff to him from playing ballet is $\left(1-w_{t}\right) B$, which is clearly less than $B$. In period $(T-1), \ldots$ [xxx continue with induction] 
[xxx What I will go on to show: If there is small probability of the man benig constrained, the Ballet ballet eq. turns into a War of attrition. the mixed strategy eq. switches over too. The War of attrition eq. stays the same.

Maybe I should do some numerical examples. ]

\section{The Incomplete Information Game}

1. Ballet, ballet is no longer an equilibrium. The man would deviate to fight, and the woman's best response is to imitate him, thinking he is constrained.

2. Mixed strategy eq. There is still an equilibrium like this. But as the man plays fight more, the woman will assess greater probability of him being constrained. If he does fight enough times in a row, she will switch to fight.

Consider a mixed strategy equilibrium in which the man player fight with probability $m_{t}$ and the woman with probability $w_{t}$. Denote the woman's assessment of the probability that the man is constrained by $p_{t} . p_{1}=p$. If the man ever plays ballet then $p_{t}=0$ thereafter. If when unconstrained he mixes with a probability $m_{1}$ of playing fight in period 1 and does choose fight, then using bayes's rule,

$p_{2}=\operatorname{Prob}($ constrained $\mid$ fight $)=\frac{\operatorname{Prob}(\text { fight } \mid \text { constrained }) \operatorname{Prob}(\text { constrained })}{\operatorname{Prob}(\text { fight })}=\frac{1 * p}{1 * p+m_{1} *(1-p)}>p_{1}$,

and in general if the man has always chosen fight up to $t$ then

$$
p_{t}=\frac{1 * p_{t-1}}{1 * p_{t-1}+m_{t-1} *\left(1-p_{t-1}\right)}>p_{t-1} .
$$

Thus, $p_{t}$ is increasing in $t$ so long as the man always plays fight.

The woman's expected payoffs are

$$
\text { Woman'spayof } f(\text { fight })=p_{t} B+\left(1-p_{t}\right)\left[m_{t} B+\left(1-m_{t}\right) 0\right]
$$

and

$$
\text { Woman'spayof } f(\text { ballet })=p_{t} 0+\left(1-p_{t}\right)\left[m_{t} 0+\left(1-m_{t}\right) A\right]
$$

Equating these,

$$
p_{t} B+\left(1-p_{t}\right) m_{t} B=\left(1-p_{t}\right)\left(1-m_{t}\right) A
$$

and

$$
m_{t}=\frac{p_{t} B+\left(1-p_{t}\right) A}{\left(1-p_{t}\right)(A+B)} .
$$

This value of $m_{t}$ would be the same as for the complete-information game if $p=0$. Otherwise, it is less, and it is decreasing in $p_{t}$. Oddly enough, the unconstrained man plays fight with lower 
probability the greater the woman's belief that he is constrained and must play fight. That is because the man's mixing probability must make the woman indifferent between fight and ballet as pure strategies, and for this to happen when she believes he is more likely to play fight as a constrained player he must be less likely to play fight as unconstrained.

Since $p_{t}$ increases with $t$ if the man always chooses fight, $m_{t}$ falls. As a consequence, $p_{t}$ not only rises, but it does not approach any asymptote less than 1 , as it might if $m_{t}$ fell as $t$ rose. For large enough $p_{t}$, the woman's payoff from fight is equal to that from ballet even if $m_{t}=0$, as equation (17) becomes:

$$
p_{t} B=\left(1-p_{t}\right) A
$$

This occurs if $p_{t}$ rises to $\frac{A}{A+B}$. Let us denote the period in which that occurs as period $S$. In period $s$ and after, if the man has played ballet throughout, the mixed-strategy equilibrium must break down and the woman will play fight.

Consider, however, the man's incentive in period $(S-1)$. He knows that if he plays fight for just one period, the two players will play (fight, fight) for the remaining $(T-S)$ periods, whereas if he plays ballet they will revert to the complete-information mixed-strategy equilibrium. An upper bound on his total remaining-game payoff if he chooses ballet is

$$
\text { man'spayof } f(\text { ballet })=B+(T-S) \frac{A B}{A+B}
$$

A lower bound on his total remaining-game payoff if he chooses ballet is

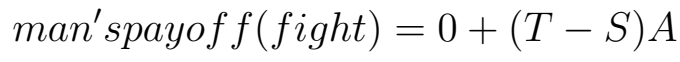

The value of $S$ is independent of the $T$, the total length of the game. If the game is long enough, $(T-S)$ will be great enough that fight dominates ballet whatever mixing probability the woman may use in period $S-1$.

Conjectured mixed-strategy equilibrium: they mix for S periods, then go to fight, fight if the man has never chosen ballet.

Disproof: Consider period S-1. The man has a strong interest in choosing Fight then, because he will be the victor. So if (T-S) is big enough, he will choose Fight in S-1. But then the woman will choose fight in S-1 also. That means he has an even stronger incentive to choose Fight in S- 2. We can induct backwards to FF.

What about two-sided uncertainty? I can show that no mixed-strat. eq. exists. It would have to give one or the other of them an incentive to go to $\mathrm{S}$ periods to become victor, adn that would

\footnotetext{
${ }^{2} \mathrm{xxx}$ But could there be a Benoit-Krishna eq. in which there is arbitrary behavior and then punishment? That is one without mixing in every period, though. Even then, my statements hold true. Periods in which there is no mixing- just Fight as a pure strategy- would have no chnge in $p_{t}$, though.
} 
make the other back down. The fact that BOTH would back down is not relevant. The eq. makes no sense. There CAN be a pure-strategy eq. now- if either player backs down and makes the other the victor immediately. But what kind of out-of-eq behavior si needed?

3. Attrition equilibrium. Conjecture: they mix, and if they go the full S periods, the man becomes the victor.

Disproof: as in the mixed-strat. eq., the man would persist at S, and the woman would give up early.

What about two-sided uncertainty? It seems it rules out the attrition equilibrium also.

[the repeated BS is like repeated bargaining,but simpler.] J Kennan, R Wilson Bargaining with Private Information Journal of economic literature [0022-0515] Kennan yr:1993 vol:31 iss:1 pg:45

Suppose there is probability $p$ that the man is constrained to choose fight. What happens to the (ballet, ballet) time-independent equilibrium? The strategy combination (ballet, ballet) in each period is no longer an equilibrium outcome, because the woman's best response to the man's choice of fight would be to herself choose fight.

The closest to that equilibrium would be for the woman to start by choosing prizefight with probability $w(t)$ and the man with probability $m(t)$, each probability depending on $t$, the number of periods that have elapsed with the man choosing prizefight. If the man ever chooses ballet, then the fact that he is free is revealed, and both players choose ballet thenceforth. If the woman ever chooses prizefight, she continues to do so to the end of the game. Thus, we have a war of attrition.

Let the expected payoff from the rest of the game to the man be $V_{m}(t)$.

On the other hand, the period-by-period mixed-strategy equilibrium also changes. Now, the more the man picks prizefight, the more likely he is to be constrained. This means the woman will eventually come to believe he is constrained, and will choose prizefight thereafter. This gives the man more incentive to choose prizefight than he previously had...

If the man ever chooses Ballet, let them revert to the mixed-strategy equilibrium. If the woman chooses The payoff to the man must be equal from each pure strategy, so

$$
\pi_{m}(\text { prizefight }, t)=w(t) A+V_{m}(t)=\pi_{m}(\text { prizefight }, t)=
$$

The idea that there is uncertainty associated with a game thus lends support to the idea that the equilibrium in the battle of the sexes will be a mixed-strategy one - though it points to the war of attrition equilibrium rather than the period-by-period mixed-strategy equilibrium.

\section{Closing Remarks}


This could be tested against the Focal Optimality Theory, whether by introspection or experimentally, with the following modification of the game.

The constrained strategies are limited to $z<80$. The Incomplete info explanation predicts $x=80$, but the Focal Optimality Theory continues to predict $x=100$. Of course, we have a new focal point too, so the test is not pure. 


\section{References}

M Bacharach (1993) "Variable Universe Games," Frontiers of Game Theory, 1993

Benoit, Jean-Pierre \& Vijay Krishna (1985) "Finitely Repeated Games," Econometrica, 53(4): 905-922 (July 1985).

Carlsson, Hans \& Eric van Damme (1994) "Global Games and Equilibrium Selection Hans Carlsson," Econometrica, 61(5): 989-1018 ( September 1993).

Crawford, Vincent P. \& Hans Haller (1990) "Learning How to Cooperate: Optimal Play in Repeated Coordination Games," Econometrica, 58(3): 571-595 (May, 1990).

Binmore, Ken \& Larry Samuelson (2005) "The Evolution of Focal Points," Wisconsin working paper, March 15, 2005. http://www.ssc.wisc.edu/ larrysam/publications/focal903.pdf.

Glenn Ellison (1993) "Learning, Local Interaction, and Coordination," Econometrica, Vol. 61, No. 5. (Sep., 1993), pp. 1047-1071.

Fudenberg, Drew \& Eric Maskin (1986) "The Folk Theorem in Repeated Games with Discounting or with Incomplete Information," Econometrica, 54(3): 533-554 (May 1986).

Goyal, Sanjeev \& Maarten C. W. Janssen (1996) "Can We Rationally Learn to Coordinate?" Theory and Decision, 40: 29-49.

Goyal, Sanjeev \& Maarten C. W. Janssen (1997) "Non-Exclusive Conventions and Social Coordination," Journal of Economic Theory, 77: 34-57 (1997).

Janssen, Maarten C. W. (2001) "On the Principle of Coordination," Economics and Philosophy 17(2): 221-234.

Janssen, Maarten C. W. (2001) "Rationalizing Focal Points," Theory and Decision, 50: 119148.

Learning, Mutation, and Long Run Equilibria in Games Michihiro Kandori; George J. Mailath; Rafael Rob Econometrica, Vol. 61, No. 1. (Jan., 1993), pp. 29-56.

Kreps, David, Paul Milgrom, John Roberts, \& Robert Wilson (1982) "Rational Cooperation in the Finitely Repeated Prisoners' Dilemma," Journal of Economic Theory, 27: 245-252 (August 1982).

Lewis, David (1969) Convention, Harvard University Press, Cambridge, Mass.

Morris, Stephen \& Hyun Song Shin (2003) "Global Games: Theory and Applications," in Advances in Economics and Econometrics (Proceedings of the Eighth World Congress of the Econometric Society), edited by M. Dewatripont, L. Hansen and S. Turnovsky. Cambridge, England: Cambridge University Press (2003). 
Sugden, Robert (1995) "A Theory of Focal Points," The Economic Journal, 105(430): 533-550 (May 1995).

H. Peyton Young The Evolution of Conventions Econometrica, Vol. 61, No. 1. (Jan., 1993), pp. 57-84.

\section{WHAT NEEDS TO BE DONE:}

1. Do the $\mathrm{N}=3$ and $\mathrm{N}=4$ cases.

2. Finish the comlpete info Battles of the Sexes analysis. In particular: How do the total payoffs compare?

3. Do the incomlpete info Battle of the Sexes analysis. 